\title{
Punk, Fashion and Aesthetic Cosmopolitanism
}

\author{
Paula Guerra* \\ Faculty of the Arts and Humanities, University of Porto, Portugal
}

*Corresponding author: Paula Guerra, Department of Sociology, Faculty of the Arts and Humanities, University of Porto, Portugal.

Received Date: August 16, 2019

Published Date: August 22, 2019

Abstract

In this article we propose an analysis of the genesis of Portuguese punk fashion. Due to the overvaluation of the London reality, punk clothing may at first sight show a homogeneity. However, by considering different realities and socio-historical contexts, it is possible to establish a more detailed view of what was and what is punk fashion, and the constant appropriation and actualization of this aesthetic. In Portugal, in the years after four decades of dictatorship, this fashion constituted a form of disruption. Through a set of interviews with key actors of the Portuguese punk scene, we will try to determine how this disruptive fashion was triggered and also how it allowed the country's aesthetic and cultural opening to a late modernity.

Keywords: Fashion; Punk; Do-it-yourself; Aesthetic cosmopolitanism

Abbreviations: KISMIF: Keep It Simple Make It Fast! Project; DIY: Do-It-Yourself

\section{Introduction}

Fashion and punk. Few styles have provoked (and still provoke) both an appeal and an aversion as punk does. Aversion was even pursued by the punks themselves, and that's something that makes the appeal even stronger. It is a cycle. Therefore, it is not surprising there are numerous books, articles, journalistic works, photo books, etc. about this theme. Ironically, in a counter-punk way, this avalanche of information on punk aesthetics eventually crystallized a punk outfit with such a striking visual force that still endures today. But it creates and recreates itself in an unbroken circle since the late 1970s. Punk has fueled innovation in fashion and contemporary visual imagery in a spectrum of incessant resurrection and death [1,2]. In terms of ideology, punk assumes itself as a contesting movement in the artistic, economic and social dimensions. It was, in Western societies, a landmark of rupture and repositioning in relation to the existing social structure accompanied by a soundtrack and a visual imaginary. It was more than just a t-shirt or a song. It was an un-submissive attitude that broke the status quo and gave visibility to a youth that was unsatisfied and disbelieving the future [3].

And what was the context that allowed the emergence of punk? The genesis of punk is often interpreted by the context of economic crisis that violently hits western nations in the wake of rising oil prices. At that time, the last bastions of Great Britain's economy were sinking: the automotive and textile industries are struggling with enormous difficulties, as so the coal and metallurgy industries. Prices raised up, wages stagnated, and unemployment increased. Hebdige, et al. [4] interpreted the punk style as a visual response to England's socioeconomic crisis during the late 1970s [5,6].

The purpose of this article is to analyse the subversive and disruptive characteristics of punk fashion and aesthetics in Portugal. What are its specificities and similarities to the British reality that we mentioned above? How was that appropriated in a small country, completely isolated by 40 long years of dictatorship? As we will discuss in more detail throughout the text, the Portuguese socio-political context was quite different. On April 25, 1974 the Revolução dos Cravos [Carnation Revolution] occurs, which means the end of 48 years of political dictatorship carried out by the Estado Novo regime [3]. A revolution had taken place, but a cultural and customs revolution was yet missing. Fashion is a paradigmatic example in this matter. Immediately after the April 25, 1974 revolution, fashion had not changed significantly. There was a dress code, so to speak, normative. For men, the colors did not differ much: blue, black or white. What came from abroad was expensive and arrived often with delay. Hence the importance of punk in providing a universe of aesthetic possibilities to a group 
of young people through Do-It-Yourself (DIY) (there were also a few who could buy fashion accessories on trips to London, but they were reduced in number).

It is well known that one of the major sociological concerns is to assess how the diffusion of fashion takes place. Is it from top to bottom or vice versa? Is it a structured process or the sum of random events and actions that puts a style on the spotlight? Crane, et al. [7] considers that currently it is a highly complex process due to the geographical dispersion of the various actors involved and the huge diversity of products generated. There are two best known sociological theories on this subject. The classic model was postulated by Simmel, et al. [8]. A stylistic novelty would first be adopted by the upper classes and then progressively spread to the remaining social classes. Styles appeared in haute couture houses and over a period of time reigned there. But soon those styles were beginning to be imitated either by peers or by other social classes. By the time fashion reached the bottom of the social structure, it was depleted. Fashion is here associated with social status. Its legitimacy is only convertible into capital if its expansion is restricted. When social closure is broken, legitimacy is lost. It would be a top-down model. The second theory is based on the opposite. It defends a bottom-up model. The new styles would emerge in the lower classes and would be progressively adopted by higher social groups of the social scale [9]. Prestige is no longer associated with social status but with age. New fashion styles come from youth groups. Subcultures and youth tribes, above all. These subcultures have distinctive ways of dressing, one that attracts the eye of the fashion industry and imitation by other social and age groups [10]. These novelties would come not only from the young but also from artistic and minority groups such as homosexuals.

In both models, however, diffusion processes are accelerated by the media. In the nineteenth century, fashion needed some time to spread, not only in the country of origin, but also abroad. With the mass media, however, the whole process underwent a profound acceleration. The first model was dominant in Western societies until the 1960 s, when demographic and social factors accentuated the influence of young people in all social classes. The baby boomers were a generation with economic possibilities that were unthinkable for their parents, and this factor influenced many spheres, namely fashion. Since then, the second model explains better the reality of fashion in Western societies. Before we talk about subcultures and punk in Portugal, it is important to analyze in what context punk fashion ultimately emerged. Concretely, what was fashion like in the 1970s in the Anglo-Saxon world? For Steele, et al. [11], the style of the 1970s was some kind of bastard son of the 1960s. It unveiled a confused revolt against his ancestor. One thing needs to be said. In the 1970s, fashion was not in fashion. Or rather, anti-fashion was in vogue. Mainly, freedom to use whatever and wherever one wished was the essential requirement. Fashion of the 1970s can be divided into two phases: the first, from 1970 to 1974 , is characterized by the continuation of many late 1960s features such as retro costumes, shocking clothing and ethnic influences.
Valerie Steele, et al. [11] calls this phase the 'late hippie diffusion'. The second phase goes from 1975 to 1979, and fashion became both harder and more conservative. At street fashion level, hippie, peace, and love were suddenly replaced by punk, sex, and violence. On the other hand, in haute couture, prevailed the decadent style of terrorist chic [5]. At the same time, and paradoxically, there was a search for uniformity around dress-for-success clothing $[6,11]$. There were two main trends in this decade: androgyny and punk. This is explained by the continuing importance of music in fashion's domain. Just as mods and hippies created their own styles, so did punk. It was an aggressive style of confrontation, with an outfit marked by references to sadomasochism. Above all, it was against the remaining hippie remnants that they existed $[5,12,4,13]$. Punk was riot. The clothes were cut, pierced with pins, decorated with swastika images or tampons. It was a shock. Quickly, however, the shock passed into a major influence on the fashion world. With punk, it had become a spurious task to seek to establish strict separations between anti-fashion and fashion [14].

Although part of a broader context of cultural production, and as a consequence of constraining time and space, we will focus very briefly solely on the importance of Vivienne Westwood. In 1971, Westwood and Malcolm McLaren rented the back of Paradise Garage at 430 Kings Road. Initially named Let it Rock, they sold rock'n'roll records and teddy boys-style clothes designed by Vivienne. Then began ten intense years of subversive creativity. Regardless of the various incarnations of Vivienne and Malcolm's store, the common catalyst for their creations was the revolutionary and anarchic attitude and the struggle for a new aesthetic. In 1973 there was a new name change: Too Fast to Live, Too Young to Die. But it is the following year, in 1974, that the store is renamed: Sex $[15,16]$. Here, rising above any measure of comfort and social selfindulgence, Westwood operates a visual poetics of deconstruction and chaos, materializing in the wearables a certain esprit d'époque that beckoned the loss of stabilizing social and cultural coordinates. Operating incisions, tears, and violations, Vivienne inaugurates an unprecedented empiricism that deconstructs the very market organization of a ready-to-wear market by appropriating massbought black t-shirts and remastering them. In these t-shirts, Westwood performs what would become the look of punk, inseparable from the urgencies of the time [17].

It is possible to identify today all the cultural and symbolic matrix of Vivienne Westwood's creations. For example, from a small shop on Kings Road to Paris, Westwood has enhanced her influence in the fashion world by gradually joining a circuit. Often accused of selling out to the system she once criticized, Westwood became between the 1980s and 1990s a global, millionaire venture; despite its virtual belonging to the capitalist logic of production, Vivienne's aggressive and ironic aesthetic still carries that old noise of (in) contestation, transmuting the catwalk's sacrosanct space into a platform for debate and protest $[15,18]$. That's why Theresa May - the former English Prime Minister - was wearing a 'classic' Westwood tartan at her swearing in ceremony in 2016. 


\section{Materials and Methods}

The data presented and discussed here is the result of a long research that lasted from 2012 to 2017. A set of 214 semi-structured or biographical interviews, conducted between 2013 and 2015, were performed to self-representing actors as punks or linked to the development of Portuguese punk scenes. The 214 interviewees of the KISMIF project have in common the present and/or past participation in the Portuguese punk scene: either as musicians, or as promoters, editors, critics and other intermediaries, or as consumers. The interviews were guided by a script with more than 50 categorical entries. The interviews were transcribed and object of a classic analysis of content and/or other quantitative and/ or qualitative speech treatments. The sample was constructed by the snowball method, following the contact networks between the actors, from an initial base referenced by the research team. The analytical object was established through the contacts provided by the interviewees, which gave the research a wide territorial range. Our methodology was shaped by the categorical content analysis so as to grasp the meanings and purposes of social actions, thus favoring qualitative and intensive perspectives. Our approach methodology focuses on (sub)cultural analysis. Hebdige, et al. [4] argues that after World War II there was a profound change in the way social classes were experienced in England. Especially due to changing structural factors: the media, work, leisure and education, the increased purchasing power of young people, among others. One effect of these changes was the fragmentation of discourses about what it meant to belong to the working class. These new speeches were different from the traditional ones. From the perspective of the Centre for Contemporary Cultural Studies, the emphasis was on how subcultures sought a solution for the problems affecting working-class youth. Those solutions could not overcome the fact that these individuals were in a subordinate position in the social structure. This tension, especially striking in a hierarchical society like the English one, was reflected in the form of subcultural style [4].

Subcultures can be defined through concepts such as DIY and homology. The first leads us to the new meanings that subcultures attribute to objects, while the second relates to the connection, the homology between the symbolic dimension and the material dimension of subcultures. In other words, the objects associated with a given subculture acquire their own meaning for its members, reflecting or expressing its explicit and implicit values [19]. Considering the punk subculture, Hebdige, et al. [4] explores its dimension of refusal and revolt against the socio-economic conditions in which working-class youth lived, stressing out that it was largely asserted by the style that functioned metaphorically as a weapon against the ruling class, as well as the fact that no subculture has managed to further break with dress norms and no subculture has so actively caused social disapproval to fall upon itself as punk did. It should be noted that wearing or using a garment is not, by itself, synonymous with style. There is the need for a stylization process, a conscious organization of objects, a repositioning and recontextualization, which removes them from their original context and thus enables new readings and resistances. It is precisely through this process of stylization that subcultures communicate their forbidden messages and meanings, as well as their collective identity [20].

Taking the Gramscian concept of hegemony, it can be argued that subcultures become symbolic forms of resistance, substantiating what we might term a semiotic warfare. Hebdige, et al. (4) evidently points this out by stating that subcultures can be seen as an annoying, dissonant and divergent noise from the dominant tone. A resistance under - a double - attack: on the one hand, the resettlement and subsequent sale of the subculture style by the market; and, on the other hand, the media's redefinition and ideological interpretation [21]. That said, can these subcultures eventually be incorporated into the dominant culture to which they oppose? As it is well known, every time a spectacular new subculture arises, there is a sequence of amplification and a reaction that usually varies between two extremes: fear and fascination. This sequence of amplification invariably ends with the deactivation and massification of the style of the subculture in question. It is framed in what Geertz [22] calls the map of dense social realities or, in Hall's [23] assertions, a dominant frame of meanings. This is a process that embodies two dimensions: a market, in which there is a conversion of the various symbols of a given subculture into mass products; and an ideology, a form of "labelling" and "redefinition", by the dominant groups and their own apparatus, such as the media, the police force, and the judicial system [4]. It may be added that Hebdige, et al. [20] was also concerned with the evolutionary dynamics of subcultures, discussing the nodal question of the authenticity of artistic creations. Many of the subcultures emerge as a replacement for previous subcultures, which disappeared through their assimilation by the dominant culture, in a context of commodification of its structural aspects (clothing, music, etc.), becoming massively produced objects, introduced in the hegemonic life style, and redefining its deviant status. The big question is: how far is this from a realistic perspective? Was there a homogeneity in punk style? Did all punks master subversive aesthetic codes? Could all punks trace the theoretical background of their clothing, from surrealism to situationism?

Cartledge, et al. [24], drawing from his own experience as punk in Sheffield in the 1970s, refutes the main lines pointed out by subcultural theory. There is a need to counteract the simplistic view we are offered of punk. First, a textual and visual perspective that focuses on the city of London and its bands, actors and avantgarde shops; the second focuses on the reading of punk style as a form of ideological resistance. Both perspectives were important in creating a fixed punk iconography. The problem is that these readings imply linearity that makes spatial differences secondary. This creates a narrative in which the punk style is characterized by a homogeneity for the simple reason that it focuses solely on a city and a small group of people. The truth is that in urban cultures of that time homogeneity did not exist. And if we look at the small towns distant from the big centres, and if we look at their clothing 
stores, bars and clubs, it is possible to learn how a new youth cultural code, punk, has evolved and expressed itself through a process of consumption. Local cultural productions were marked by the intersection between the punk fashion media representations and the DIY ethos. Initial contact with punk was roughly through bands and musical media. With this a form of dressing emerged dependent on DIY know-how, as well as on shopping at the few clothing stores available or mail ordering. Thus, in small venues, the flow of fashion information depended on a range of spaces, such as bars and clubs. Young people went to see punk bands and that provided them with a pattern they could emulate. Other sources of information were magazines, where it was possible to find pictures of punks and to draw ideas and influences from there; second, in these magazines there was advertising for punk clothing and accessories [24].

All of this made the local punk fashion grow and change, but always linked to a wider cultural system. There was a synthesis between mainstream and underground. For the sake of ease, Cartledge, et al. [24] postulated five phases of punk fashion:

(1) In 1975, a pre-punk style was experimented, influenced by David Bowie and Roxy Music, and by DIY experiments; (2) Between 1975-1978, the focus was on exclusive London style and stores such as Sex and Seditionaries'; (3) Between 1976-1979, an urban dark style emerged and coexisted with the previous one, based on experimentation and DIY alterations, such as plastic sandals, homemade t-shirts with slogans or band names, military clothing, etc.; (4) From 1979 onwards, the most well-known punk outfit, partly derived from rock outfit, shows the prominence of leather jacket, Dr. Martens, and bondage pants, among other things; (5) from 1980 onwards, much is the same as the previous point, only with ever more exaggerated Mohawks, more extreme body piercings and modifications, as well as a more marked style by political doctrines.

\section{Everything was More Than a T-Shirt}

Style is a crucial feature in punk scenes. The Portuguese reality proved to be no different. But the social context in which he grew up was quite diverse. It is pertinent to remember that Portugal, in the 1970s (and practically until the 1990s), was characterized by a lack of cultural and stylistic goods. If so in the major cities of the country, imagine how it would be like in medium and small cities. This led to the Portuguese punk waging above all on DIY philosophy. The scarcity of cultural and stylistic goods did not respond to their subcultural needs. They had to create those goods. We are not talking about records or entertainment venues (which were only a few), but rather more prosaic things like ready-to-wear clothing. Sometimes simple pants and t-shirts [12,25, 26]. All this led to aesthetic options of the Portuguese punks oriented by different strategies compared to their English, European or American peers. There was a higher incidence, for example, of DIY practices [1]. That is, if there were no places to buy clothes, they had to be made at home. Another issue helped this, which can be explained by Pierre Bourdieu's 'love for the need' [27] - Portugal was then an impoverished country, and unlike the European and American youth, the Portuguese had very limited financial resources. Hence the need to be creative, as we will see with the excerpts presented forward. An initial analysis allows us to establish two different forms of access to punk style [28,5]. First of all, it should be noted that, in the early days of punk in Portugal, rather than a class claim, it was intended an affirmation of a more transversal change of values, involving an opening of the Portuguese youth to new songs, new aesthetics, new forms of sociability.

The genesis of this movement took place in Lisbon in small groups of middle/upper class young people, whose travels to the United States and to the United Kingdom allowed them to get in touch with new sounds and aesthetics, namely the punk. Not surprisingly, the epicenter of the Lisbon punk scene was Alvalade, an area of the city inhabited by urban middle-class families. They were young people who could travel and attend festivals abroad, as well as buying imported records, magazines and punk fashion. Here is evident the conversion of cultural capital into subcultural capital. In the Portuguese case, accentuated by the scarcity of goods and subcultural infrastructures. Therefore, the first form of access to punk aesthetics was a direct one: travelling abroad was the opportunity to buy punk clothing (as well as records and magazines). It should be noted, however, that this form of access is statistically minor. Correspondently was also extremely valued. The allure of having an official Dr. Martens, even if in second hand, was not to be underestimated. It was an objectified subcultural capital [29]. The access was so difficult that it was not surprising the reaction they provoked: many said they had not dropped their boots for days. Certain respondents still keep these accessories decades after their purchase.

It was almost inaccessible. When someone had the opportunity or possessions to travel, he was almost idolized for having, for getting such things. I, at least, idolized... But because these things were so difficult to access, they still became more valuable, more coveted, more desired. And then when we made it was such a pleasure. I remember when I bought my first Dr. Martens, which were bought second hand, I don't remember where, that was such a pleasure, it was a really extraordinary thing for me [smile], it was great! (Excerpt from interview with Helena, 55 years old, graduated, teacher, Lisbon).

Going abroad was a shared event with everyone. Those who stayed in Portugal, but who had money to spend, asked those who went to bring this or that. From simple actors they became subcultural intermediaries of the scene. Likewise, the fact that Portugal was a country of emigration helped to obtain cultural goods that were scarce in the country. A peculiarity is that, as Portuguese emigration at the time was essentially prevalent in French-speaking countries, the goods came from markets that are not normally associate with punk aesthetics: France, Belgium, etc.

We did it ourselves, or had it come from outside. Those who could, ordered it from abroad. I even ordered some boots [laughs] [...] From time to time, I would go to Belgium to see my parents. In 1986 I was also loading clothes here (Excerpt from interview with Joana, 49 years old, graduated, artist, Porto). 
Ah I remember that my mother went to Paris for a vacation and I asked her: "Bring me a bullet belt, mother! Bring me a bullet belt, mother!".

And I remember she told me that she had been walking a lot with a cousin of mine, who had been with her helping to find out where they could find it and brought me the bullet belt that cost thirty euros at the time. Thirty euros at the time! It was big money! I still keep it to this day. Obviously, I won't get rid of it (Excerpt from interview with Virginia, 48 years old, graduated, actress/teacher, Lisbon).

Another form of direct contact with the punk style was made in Portugal: through the few stores that imported this material. Prices, due to customs duties, were prohibitive. But the role of these stores is not to be devalued. Not only for those who went there to buy, but also for those who were there to admire the latest news from England and, having no money, would think of alternatives to create something similar. With or without money, these stores were a milestone in the face of Portuguese aesthetic greyness. And they are still present in the collective memory of the Portuguese punks. Such as the Rastilho record store [9], which also sold accessories like patches and spikes, which were later sewn by punks. One of the best known was the Porfírios clothing store [10], situated in Lisbon. Inaugurated in 1965, it was perhaps the only space specialized in youth clothing in Portugal. In this case it was not imported clothes, since everything was made in Portugal, but rather an imitation of the news that occurred in Carnaby Street. It was a key place for the incipient Portuguese youth cultures to know about what was happening abroad.

At the time, there was a distributor that was Rastilho, which had been around for a long time, and we bought the patches and sewed them ourselves. I sewed everything by hand. We sewed everything. [...] I only did, in jackets, paint with a white paint that we had, we painted directly on leather jackets. In coats it was all patches. We bought the patches and we sewed. Basically, it was like this (Excerpt from interview with Lazarus, 37 years old, 3rd cycle of elementary school, funeral helper, Guarda).

But later that time there were no trips to London either. At this age we couldn't, we were underaged. We went to the Porfírios to buy the coats, the peaks there at the foot of Martim Moniz. Then we would pick the peaks, the badges we would buy at Feira da Ladra Flea or Porfírios. Porfírios had the coat we liked, but then we had all the flea market for army boots (Excerpt from Tobias interview, 46 years old, college student, graphic design and communication technician/video artist, Almada)

Analysing this mixed aesthetic, we cannot fail to mention the (slow) changes that were happening simultaneously in Portuguese fashion, greatly influenced by the novelties and punk and post punks' sensibilities. First, the Maçã [Apple] store, founded in 1972 by designer Ana Salazar [11], that sold clothes imported from London; then the 1980s cultural revolution that took place in Bairro Alto [12], with the founding of mythical spaces such as the Frágil [Fragile] club. In this way, a sort of revolution took place and became the display of a new aesthetic. Associated with this also occurred the event Manobras de Maio [May Manouvers] [13]. It was a stage mounted to serve as a catwalk for professional and amateur mannequins. In this case, all was very similar to a punk concert: the audience was practically on top of the mannequins. There were no barriers, nothing to separate the public from the models [30].

\section{Cities, Routes and Resources, or the Light at the End of the Tunnel}

Most Portuguese punks were guided by the second aesthetic consumption strategy: DIY. A form of subversive consumerism, as McRobbie, et al. [31] underscores, in which the inequality inherent to the fashion world is subverted by the reconversion of secondhand clothing. This brings Portugal closer to the reality of small English cities. As Cartledge, et al. [24] analyses, when we think of punk fashion we immediately talk about London. But only a small number of agents are overrated, not the majority of the punks, who lacked the financial capacity to go to Vivienne Westwood's stores. So, in Portugal, what happened was a true pilgrimage along a second-hand clothing circuit. After purchasing these clothes, they either sought to imitate or to create a style out of the little information they could glimpse in magazines and/or fanzines. In some cases, it required a lot of imagination to find alternatives to objects that would be excessively expensive in the market or to save money for other consumptions, such as records.

But what are the most emblematic spaces of this circuit? First, and paradoxically, their home. There was almost a rite of passage that involved rummaging through the chests of grandparents and parents for clothes that could be worked on. It was the easiest and cheapest option. Secondly, the charity or secondhand clothing stores. At a time when vintage was not in vogue, these harnesses nevertheless implied a social stigma. Going to charity or secondhand shops was associated with precarious ways of life. Regardless of all, these stores made it possible to buy clothes by the kilo at a very low price. It allowed an almost unlimited supply of material to convert. And this is important also in other respect: when we talk about DIY, we usually only take into account the practices that were successful, however, there was much trial and error here. Before they got the process right, a lot of clothes were damaged. Hence the need to find places where they could buy real bargains.

Portugal had compulsory military service until 2004. Ironically, military conscription implied large amounts of military material that was not always needed, or could not be used again by the troops, and was eventually sold to second-hand shopkeepers. It was in these stores that the Portuguese punks could get their military boots to replace the very expensive Dr. Martens; leather jackets, since Porfírios stores were not accessible for everyone; and the military pants that were later worked on, among other military articles. No place, however, had the importance of Feira da Ladra Flea Market (Lisbon) and Vandoma Flea Market (Porto) [14]. Those were places of intense sociability and crucial to punk fashion. The same can be said about the Lisbon Flea Market: a meeting place, 
usually on Saturday mornings, and at the same time the only place available for punk purchases, namely second-hand clothing which they then re-appropriated. We are talking about a DIY logic that referred, first, to an affirmation of individuality and, second, to a 'love of the necessary', as a consequence of the lack of alternatives in ready-to-wear or clothes that differed even slightly from the normal pattern.

But I remember going to Porto several times, buying a scene that was from São Vicente [15]. Hey, one of those scenes that people give clothes to and then you can go and buy it. We would buy a kilo of old clothes that we were looking for, we would bring and then many things that we would sew or glue in everything. Yes, I remember there was a time when we were doing this. All super cheap. [...] Because you couldn't find clothes that we could identify with or like, we ended up buying and changing and modifying it all (Excerpt from an interview with Benedita, 43 years old, graduated, teacher, Coimbra).

After second-hand shopping, the experimentation phase began [31], sometimes a sui generis experimentation. For example, because hair gel was expensive, soap and sugar did the trick. There were no studded belts? Then the blacksmith would put the nails in the belts. In this process of experimentation, we must highlight the careful attention given to the image. Symptomatic of this are the hours spent in getting your hair up; the collective work of preparing to go out at night or especially on punk concert occasions. Or the collective outings through the cities, with clear intentions to shock people. But also, on the other hand, an exercise of appropriation of public space, which in many cases was forbidden to them, and, at last, a form of defense against attacks directed at punks when walking alone or in small numbers.

I remember going to the Nina Hagen concert at the Alvalade Pavilion and we all met in the Jardim dos Coruchéus [17], I was there doing the hairstyles, doing the Mohicans, someone took the hairstyle machine and the people...There was a cult of the image that was lost a little, that was lost... (Excerpt from interview to Virginia, 48 years old, graduated, actress/teacher, Lisbon).

One of the first places we met was here in Lisbon, at Praça do Comércio [18], when there were still cars parked in Praça do Comércio. We would meet there, at the statue, and then go for a walk around Lisbon. It was like that scene of punks walking down the street, we were going to show ourselves [laughs] (Excerpt from Tobias interview, 46 years old, university student, graphic design and communication technician/video artist, Almada).

Here one could see both individualism and punk mimicry, which is not surprising. In a society where little information was available about the outside, it is understandable that punks would follow all the little punk fashion information they could get. With this we can be tempted to acknowledge the existence of only one punk outfit. But, in doing so, we would find ourselves very far from reality. Nonetheless we have grasped here a discussion that permeates the punk scene. On the one hand, punks who speak of a "punk uniform" in the sense of the existence of a certain aesthetic that made them recognizable: an important issue for youth subcultures, that is, the ability to recognize subcultural codes and to know that we have someone there sharing our aesthetic and subcultural sensibilities, a way to lessen one's ontological anxiety. On the other hand, others speak of 'punk uniform' as a restriction of punk individualism. This quickly falls into spurious hierarchies and aesthetic policing - the very antithesis of the punk movement. In a beautiful word choice, one respondent dubbed "little dictators" those who did not accept deviations from the "script" of what they considered to be punk clothing. Noteworthy is the relief that many felt when they discovered that they could be punks outside this script, that they did not have to carry heavy leather jackets and military boots in the peak of summer to be punks.

\section{Conclusion}

In addition to the importance of these practices for a strengthening sense of belonging, imperative for the genesis and perpetuation of punk in Portugal, it is necessary that we now refer to society's response to aesthetic innovations, to these claims of individuality and rejection of the mainstream. As we have already mentioned throughout this article, reactions were grossly negative, only varying qualitatively, from stares, ironies, insults or aggressions to the expulsion of public spaces such as cafes. This aggravated the difficulties these young people already felt in finding places where they could enjoy a subcultural experience, especially at night. The spaces themselves were already few. Most did not interest them; some, which interested them, barred their entrance. In the city of Porto, for example, this made the punks bet on the traditional taverns of the city, one of the few places where they could celebrate their punk sensibilities [32]. This gets worse if we talk about punk women: there were not so few the cases of harassment. The short and provocative clothes were in many cases understood as invitations [33]. All this has not failed to cause problems for these young people: with their family or with strangers on the street, especially in a country still uncomfortable with difference. Nor can we fail to speak of the desire of many to shock and to push punk boundaries. Thus, and as noted above, this clash with a conservative and even reactionary society, in addition to be a glimpse of a newly cosmopolitanism, has also served to strengthen the bonds of belonging and the group union.

We mentioned earlier that punk aesthetics served as an indicator of group membership and as a form of ontological security. In a society that did not welcome them, recognizing punk accessories served to reinforce group and individual identity [17]. After all, nothing is more complicated than looking around and not seeing anyone accompanying us. But how is all this when everyone is punk? In other words, how is all this when the punk outfit becomes massified? Nowadays it's easy to buy a Ramones t-shirt, a studded belt or black skinny jeans at any Zara store. This implies a profound change in group identity. Aesthetics ceases to shock, perhaps its main value, and ceases to be specific to this group. Given this, we envision a simultaneous process of appreciation/ 
devaluation. Appreciation of their subcultural trajectories and capitals, first of all. As it may be easy to understand, it is important to feel that your past, its long trajectories, had a purpose. This is where the narrative of innovation comes in, of the pioneers. Yes, it's true, everyone wears skinny pants. Yes, even TV presenters use Mohawk. Yes, DIY is in vogue and there are television shows about it. But we (the pioneers) started it. Even before it became fashionable: in the 1970s, when going out dressed like that was an adventure, and you didn't know how you would end up with insults, assaults or everyone in the police station; when the girls laughed at us when they saw us in ripped pants; when reusing old clothes was not vintage, but a poor's thing.

Individualism was one of the characteristics of punk. Being different, not following norms and rules (which was not always so aesthetically, as we have seen). So, the idea of uniformity is hard to digest for Portuguese punks. Especially when they 'all look the same' to them. It is nevertheless ironic, as one of the main arguments of Portuguese punks was the clash against the aesthetic uniformity of Portugal. Not in a million years would they think that one day their aesthetics would be everywhere. Thus, when the shock disappears, there comes a revaluation of the past, its role in history, an open mindset that society, especially in the mid-1990s, eventually coopted. It is the fusion of the melancholy of a lost time (and one that will not come back) with a sense of pride, especially when younger people recognize the role that older people played in opening up the current aesthetic possibilities. On the other hand, there is the depreciation of the uncritical adoption of punk style. There are endless ironies about the 'ridiculous' wearing of Ramones or Sex Pistols t-shirts without knowing that they are music bands. Or to use Dr. Martens without knowing the subcultural role they have played since the mid-1960s, or without knowing the joy of having them in the 1970s and 1980s. All this without even appreciating the role of pioneers in this aesthetic opening. Basically, they are also pointing out the establishment of boundaries between true and false punks. It's an attempt of social closure that allows the preservation of their capital and the valorization of their subcultural trajectories.

In a society marked by four decades of dictatorship, punk emerged as a breath of fresh air. The representations of the $1970 \mathrm{~s}$ are unanimous in the descriptions of the country as grey and atavistic. The political revolution lacked a cultural and customs revolution. In the end, punk let the long-desired cosmopolitanism evolve gradually. Punk was an essential part of introducing this cosmopolitanism, with all the difficulties we listed: difficulty in accessing cultural goods, scarcity of financial resources and social antagonism [34]. However, this allowed the Portuguese punk to be very specific, centre on DIY domains: aesthetics, concerts, albums, etc. Aesthetically speaking, punk was at the forefront of what existed in Portugal, a country with no ready-to-wear tradition and no Carnaby Street. This led to the main feature of Portuguese punk: DIY. The need to create their own clothes and styles. A plethora of time spent searching for secondhand clothing at various fairs and then gather and cut pieces. Even greater difficulties presented in consequence of a national social context that was insensitive to the manifestation of aesthetic alterity. Aside from this, or precisely because of these social features, they did not fail to create, as we read in the quotations presented, a lasting sense of belonging, of being part of a group.

This first influence began to catch the glimpses of more alternative clothing, whether it was in Ana Salazar' stores, in Manobras de Maio or in the new bohemian Bairro Alto. In all these examples, the influence of punks was outstanding. Only by the years 1990s did the situation change significantly. New ready-towear shops appeared, and clothing became less classic and more alternative. But paradoxically, for punk, this was a problem. How to shock society when resistance was co-opted by the mainstream? This is crystallized in the melancholy and irony of punks when they speak of the appropriation of punk fashion. Regardless of everything, the disruption they caused in Portuguese society has served to set a range of social issues in debate like veganism, sexism, racism and the celebration of difference [35]. And the appreciation of this, when it comes, is extremely satisfying, as one interviewee proudly refers to the moment when friends of his children praised him (and his peers then) for what he fought in the 1970s and 1980s, so allowing young people today to dress up as they wish [36].

\section{Acknowledgement}

None.

\section{Conflict of Interest}

Authors declare no conflict of interest.

\section{References}

1. Guerra P (2017) 'Just can't go to sleep': DIY cultures and alternative economies from the perspective of social theory. Portuguese Journal of Social Science, 16(3): 283-303.

2. Guerra P, Straw W (2017) I wanna be your punk: the universe of possible punk, DIY and underground cultures. Cadernos de Arte e Antropologia 6(1): 5-16.

3. Colegrave S, Sullivan C (2002) Punk. Hors limites. Éditions du Seuil, Paris, France.

4. Hebdige D (2018) Subcultura: O significado do estilo. Tradução: Paula Guerra e Pedro Quintela. Maldoror, Lisboa, Portugal.

5. Guerra P (2013) A instável leveza do rock: génese, dinâmica e consolidação do rock alternativo em Portugal. Afrontamento, Porto, Portugal.

6. Silva AS, Guerra P (2015) As Palavras do Punk. Alêtheia, Lisboa, Portugal.

7. Crane D (1999) Diffusion models and fashion: A reassessment. Ann Am Acad Pol Soc Sci 566(1): 13-24.

8. Simmel G (2014) Filosofia da Moda. Tradução: Fernando Baptista Leite. Textos \& Grafia, Lisboa, Portugal.

9. Field GA (1970) The status float phenomenon: The upward diffusion of innovation. Bus Horiz 13(4): 45-52.

10. Polhemus T (1994) Street Style: From Sidewalk to Catwalk. Thames \& Hudson, London, UK.

11. Steele V (1997) Anti-Fashion: The 1970s. Fashion Theory 1(3): 279-295.

12. Guerra P (2014) Punk, expectations, breaches and metamorphoses: Portugal, 1977-2012. Crit Arts 28(1): 195-211.

13. Clarke J, Hall S, Jefferson T, Roberts B (1997) Subcultures, Cultures and Class. In: Gelder K, Thornton S (1997) The subcultures reader. Routledge, London, UK, pp. 100-111. 
14. McKay G (1996) Senseless Acts of Beauty: Cultures of Resistance since the Sixties. Verso, London, UK. Journal of Textile Science \& Fashion Technology Volume 3-Issue 4.

15. Westwood V, Kelly I (2015) Vivienne Westwood. Picador, London, UK, p. 464.

16. Mulvagh J (2011) Vivienne Westwood: An Unfashionable Life. HarperCollins, New York, USA, p. 402.

17. Unsworth C, Mooney J (2019) Defying Gravity: Jordan's Story. Omnibus Press, London, UK.

18. Clarke JS, Holt R (2016) Vivienne Westwood and the Ethics of Consuming Fashion. Journal of Management Inquiry 25(2): 199-213.

19. Guerra P, Quintela P (2018) O resto ainda é Hebdige. In: Hebdige, Dick. Subcultura. 0 significado do estilo. Maldoror, Lisboa, Portugal, pp. 5-71.

20. Hebdige D (2012) Contemporizing 'subculture': 30 years to life. European Journal of Cultural Studies 15(3): 399-424.

21. Hesmondhalgh D (2005) Subcultures, scenes or tribes? None of the above. J Youth Stud 8(1): 21-40.

22. Geertz C (1964) Ideology as a Cultural System. Apter DE (edt). Ideology and Discontent. Free Press, New York, USA

23. Hall S (1977) Culture, the Media and the Ideological Effect. In: James C, Michael G, Janet W (edts.). Mass Communication and Society. Arnold, London, UK.

24. Cartledge F (1999) Distress to Impress? Local Punk Fashion and Commodity Exchange. ROGER, Sabin (ed.). Punk Rock: So What? The Cultural Legacy of Punk. Routledge, London, UK, pp. 143-154.

25. Guerra P (2015) Keep it rocking: the social space of Portuguese alternative rock (1980-2010). Journal of Sociology 51(1): 615-630.
26. Guerra P, Silva AS (2014) Music and more than music: The approach to difference and identity in the Portuguese punk. European Journal of Cultural Studies 18(2): 207-223.

27. Bourdieu P (2010) A Distinção. Uma Crítica Social da Faculdade do Juízo. Edições 70, Lisboa, Portugal.

28. Guerra P (2010) A instável leveza do rock: génese, dinâmica e consolidação do rock alternativo em Portugal (1980-2010). Tese de Doutoramento. Faculdade de Letras da Universidade do Porto, Porto, Portugal.

29. Thornton S (1995) Club Cultures: Music, Media and Subcultural Capital. Polity, London, UK.

30. Guerra P (2018) E nada mais foi como dantes: fragmentos contraculturais e seus estilhaços no pós-abril de 1974 em Portugal. Teoria e Cultura 13(1): 195-214.

31. Mcrobbie A (1997) Second-hand dresses and the role of the rag market. Ken G, Sarah T (edts) The Subculture Reader. Routledge, London, UK, pp. 191-199.

32. Guerra P, Xiao J (2018) A Comparison between Portuguese and Chinese Punks: A Genealogy, Style, and Space. Punk Culture in Contemporary China: 177-199.

33. Guerra P, Gelain G, Moreira T (2017) Collants, correntes e batons: género e diferença na cultura punk em Portugal e no Brasil. Lectora: revista de dones i textualitat (23): 13-34.

34. Skrbiš Z, Woodward I (2013) Cosmopolitanism: Uses of the Idea. Sage, London, UK.

35. Adorno, TW (1981) Perennial fashion - jazz. In: ADORNO, Theodor W. Prisms. MIT Press, Cambridge, USA, pp.119-132.

36. Bell C, Howe Z (2019) Dayglo: The Poly Styrene Story. Omnibus Press, London, UK. 